\title{
EPIDEMIC CHARACTERISTICS OF PATIENTS WITH COVID-19 IN RUSSIA.
}

\author{
N. Yu Pshenichnaya ${ }^{1}$, I. A. Lizinfeld ${ }^{1}$, G. Yu. Zhuravlev ${ }^{1}$ \\ ${ }^{1}$ Federal Budgetary Institution of Science "Central Research Institute of \\ Epidemiology" of Rospotrebnadzor, Moscow, Russia
}

Background: Active epidemic process in Russia started in the March, 2020 after beginning the local transmission. At the end of June approximately 650 thousands COVID-19 cases were recorded in Russia.

Aim of study: epidemical characteristics of patients with COVID-19 in Russia

Materials and methods: statistic analysis of database of COVID-19 in Russia during the first half of 2020.

Results: Majority of registered cases in a group aged 0-17 years old were mild. In Moscow and Moscow Region (MaMR) the number of these cases was $76,69 \pm 0,92 \%$, in other regions - 73,11 $\pm 0,81 \%$. That may be explained by lower testing coverage in some parts of Russia. Moderate forms among children in MaMR were registered in $23,12 \pm 0,92 \%$ and in the other regions in $26,55 \pm 0,81 \%$. Severe forms were very rarely.

Patients $\geq 65$ had severe form of disease rarely in MaMR $(20,1 \pm 0,81 \%)$ than in other parts of Russia (23,62 $\pm 0,5 \%)$. Moderate forms varied from 52,5 to 52,7\% in all regions. Mild forms were 27,4\% in MaMR and 23,7\% in other parts of Russia. In the patients aged 18-40 and 41-64 years old in MaMR, compared to other other regions, the disease was registered more frequent in mild form $(65,51 \pm 0,3 \%$ and $49,78 \pm 0,3 \%$ versus $62,56 \pm 0,3 \%$ and $42,61 \pm 0,3 \%$, respectively). A similar trend was observed within group of patients $\geq 65$ years.

There was a clear trend between the timeframe of initial appointment and severity of illness. The growth of moderate forms 1,2 times and decrease 1,9 times mild forms were registered in case of delayed initial medical service ( $\geq 5$ day and later). 
Conclusion: Majority of cases in a group aged 0-17 years old was mild. Patients $\geq$ 65 years and above were registered with a moderate and severe forms of COVID19 , what shows that this group needs a special attention.

The more severe course of COVID-19 in older age groups is consistent with observations provided by researchers from other countries [1, 2]. A similar pattern can be traced in the higher position of older people in comparison with women of the corresponding age $[3,4]$.

The biggest part of all the cases was in a group of people of employable age. This fact shows that control of restrictive measures has to be performed as a main stream in this group. In case of delayed initial medical service COVID-19 had more moderate and severe forms.

\section{Conflict of interest:}

The authors declare no possible conflicts of interest.

\section{References:}

1. Novel CP. The epidemiological characteristics of an outbreak of 2019 novel coronavirus diseases (COVID-19) in China. Zhonghua liu xing bing xue za zhi Zhonghua liuxingbingxue zazhi. 2020 Feb 17;41(2):145.

2. Caruso D, Zerunian M, Polici M, Pucciarelli F, Polidori T, Rucci C, Guido G, Bracci B, de Dominicis C, Laghi A. Chest CT features of COVID-19 in Rome, Italy. Radiology. 2020 Apr 3: 201237.

3. Jin JM, Bai P, He W, Wu F, Liu XF, Han DM, et. al. Gender differences in patients with COVID-19: Focus on severity and mortality. Frontiers in Public Health. 2020 Apr 29; 8: 152.

4. Du Y, Tu L, Zhu P, Mu M, Wang R, Yang P, et. al. Clinical features of 85 fatal cases of COVID-19 from Wuhan. A retrospective observational study. American journal of respiratory and critical care medicine. 2020 Jun 1;201(11):1372-9. 


\section{Information about authors:}

Natalia Yu. Pshenichnaya, DSci., Prof; Deputy Director on clinical and analytical work of the Central research Institute of Epidemiology of Rospotrebnadzor, Moscow, Russia; e-mail: nataliapshenichnaya@yandex.ru; ORCID: http://orcid.org/0000-0003-2570-711X;

Irina A. Lizinfeld - MD, Consultant of the organizational and methodological department of the Central Research Institute of Epidemiology of Rospotrebnadzor, Moscow, Russia; e-mail: irinalizinfeld@gmail.com; https://orcid.org/0000-0002-8114-1002

Grigory Yu. Zhuravlev - MD, resident - physician of the Central Research Institute of Epidemiology of Rospotrebnadzor, Moscow, Russia; e-mail: grigory.y.zhuravlev@gmail.com, https://orcid.org/0000-0003-2467-7000 